\title{
Celebrity Studies Today
}

\author{
Peter A. Lawler
}

Published online: 28 July 2010

(C) Springer Science+Business Media, LLC 2010

\begin{abstract}
Celebrity, being often unearned and ephemeral, is the lowest form of fame. Nevertheless, it's a real and fascinating display of personal significance in our time. Celebrities are, of course, questionable role models, but characters of strange and singular greatness such as Elvis and Michael Jackson, everyone knows, aren't really to be imitated. Celebrities, although they often have interesting political and spiritual opinions, are easily distinguished from political leaders. Celebrity, I show, is more a downside than not of democracy.
\end{abstract}

Keywords Celebrity · Michael Jackson · Elvis · American Idol $\cdot$ Al Gore $\cdot$ Britney Spears

Celebrity, in the most obvious sense, is the lowest form of fame. Being a celebrity is a sort of gift of public opinion, which is formed by no one in particular. And so celebrity is as ephemeral as public opinion itself. Celebrity is like a gift in often being unearned and somewhat arbitrary. Although it's not as mysterious and unconditional as, say, the gift of grace, being a celebrity, despite all the marketing experts in the world, continues to elude rational control.

A celebrity isn't generally infamous, although they're often adulterers and have spent time in rehab. (They can even spend time in rehab, like Tiger Woods, to be cured of the megaadultery caused by sex addition - a disorder that causes celebrities to have sex with lots of partners but not enjoy it.) Sometimes they've even been convicted of crimes, and sometimes, as in the case of the "lovable goof" ex-governor and celebrity apprentice Rod Blogojevich, their convictions are only a matter of time. But it's almost impossible for a

P. A. Lawler $(\bowtie)$

Berry College,

Mount Berry, GA 30149-0118, USA

e-mail: plawler@berry.edu murderer or child molester or tax evader to become a celebrity simply by committing spectacular crimes.

It's pushing it to call the Unabomber a celebrity, although he turned out to be a pretty thoughtful guy. The same with the abortion clinic bomber Eric Rudolph, although he turned out to be a very resourceful guy. Bonnie and Clyde might have been celebrity murderers, but without any opportunity to cash in on their fame. Today, we have more trouble than ever in connecting celebrity with hiding out or being on the run. It's certainly pushing it to regard J.D. Salinger as having been a celebrity, although we can definitely say that he (inexplicably) passed up the opportunity to be a celebrity.

One definition of celebrity, of course, is being able to cash in on one's fame. Celebrities don't go on celebrity cruises or endorse products or make public appearances for free. The often somewhat mysterious ability to make so much for doing so little is the main reason sensible people envy celebrities. Our Founding philosopher, John Locke (who did what he could to live as a celebrity while he was alive) didn't actually say work was a good or noble thing, and so we can't help but look up to people who have either worked or lucked their way out of it. Besides, celebrities so clearly are better at using their money for real fun than uptight CEOs. And fun is more fun when it's noticed; the rank that celebrity provides cries out to be displayed through its privileges. The link between celebrities and their public is the one between exhibitionism and voyeurism, a pretty impersonal but nonetheless real expression of sociability.

Celebrities say they value their privacy, and many of them surely have too little of it. They wish, like we all do, to be seen and not seen at will. In an increasingly impersonal and disconnected world, most of us have too much privacy. Privacy or anonymity or insignificance may be the thing Americans work most hard to avoid. Studies 
show that the Americans most obsessed with the lives of celebrities are particularly unlikely to participate in civic life, but that may be because they're the Americans who are particularly unlikely to have easy access to significant forms of political participation. Many or most Americans record their deeds in both words and pictures on Facebook to give their puny lives significance to a not-so-select group of friends. The life of every celebrity appears to be a Facebook page writ large with too many "friends" to count, although even the biggest celebrities, it seems, are too anxious to dispense with Facebook, Twitter, YouTube, and so forth themselves. Anyone who believes that Britney Spears is washed up or played out has to deal with the fact that she just passed Ashton Kutcher as the American with the most Twitter followers.

Being a celebrity isn't necessarily connected to an extraordinary display of virtue or excellence in accomplishment. Well, that's not quite true-Paris Hilton and Sharon Osbourne are obviously quite savvy at manipulating the media to secure their celebrity status. Reality shows have connected celebrity to quite mundane accomplishmentslike having lots of kids or losing lots of weight. Now being "The Biggest Loser" is surely something about which to be proud, but it's hardly a great enough accomplishment to really gain the deep admiration of millions of Americans. All the biggest loser does, finally, is ascend (or, better, shrink) to normalcy from being a genuinely huge loser-a person who's self-indulgently become too fat to function or even to go on living.

The biggest loser remains the biggest loser in the sense that he or she needed outlandish incentives and mass encouragement to weigh about what most people weigh. And so he or she doesn't really escape the excessive judgmentalism people have these days about the alleged vice of obesity. (Celebrities are more aware than the rest of us about the severity of that judgmentalism: They know that people demand that they use personal trainers and the latest artificial enhancements to make looking young, beautiful, and fit seem effortless. The one form of responsibility they unreservedly embrace is that it's irresponsible to let oneself go. I've read that no matter how messed up Charlie Sheen's personal life gets, he never misses a trip to the gym or a hair appointment).

Similar observations could be made, of course, about those minor celebrities who succeed on the show "Celebrity Rehab." Most Americans don't need expensive rehab to perform the ordinary responsibilities of life, although it's impossible not to admire those celebrities (from Heidi Fleiss to Rodney King) bold enough to actually get paid for displaying their (often failed) efforts at rehabilitation to millions. (The celebrity physician to the celebrities, Dr. Drew Pinsky, is obviously laughing all the way to the bank.) Some reality shows make celebrities out of people who are just stupid and borderline unsocialized, such as the aggressively inarticulate Guidos and Guidettes grinding their guts out at the Jersey Shore. It hard to believe, but it's really true, that some people actually want to be like them! (It's also true, of course, that much of the attention given to the gullible, morally confused, and not-so-beautiful Guidette Snooki is not about envy or admiration; she, like some other "reality" celebrities, excites our moral sense by showing us that not only are celebrities not better than us, they're much worse than we ordinary decent folk).

That's not to say that reality shows of a kind don't create some of our more admirable celebrities. "American Idol", the most successful of these shows, is an authentic singing competition. The finalists raked from obscurity really do have fine voices and work very hard and very intelligently to improve quickly as performing artists. The judging is an appropriately American mixture of wisdom and encouragement. The judges themselves are celebrities, but there's no pretense that any of them, except Simon Cowell, knows what he or she is talking about. Simon is the expert. The real judges, the millions and millions of Americans who vote, do in large measure take their cue from Simon, but not always. Without the popular check, Simon would become a tyrant. Without his wisdom, Americans would vote blindly for whomever they happen to like. It goes without saying that the process doesn't work perfectly in picking the best artist time and again. But it, much like the American system of government, works pretty well in reliably producing a competent, meritocratic result.

Celebrities, generally speaking, are fairly irresponsible or selfish - out for themselves. They have less reason than we do not to be. They have rare opportunities to do whatever they want whenever they want. And not having been raised (as aristocrats once were) for their privileged lives, they usually aren't good at handling that freedom. Tiger Woods's escapades are legendary only in number. His was an exaggeration of the celebrity propensity to think of oneself in the moment and then buy oneself out of the consequences later. Tiger, of course, was known as that rare celebrity who gave equally intense time to both his game and his family. And his admirable personal focus, we thought, was reinforced by his Buddhism. But it turns out his life is just another example of celebrity freedom, one magnified by being an actual billionaire.

The only reason all men, promiscuous by nature, don't live like Tiger, some of our scientists tell us, is that they're constrained by the repressive conformity of bourgeois life. That repression makes sense for most of us, certainly, because we lack the wherewithal to live without it. Tiger, of course, was cashing in not only on golfing greatness but on his "role model" reputation, and it's almost sad to think that all his (surely fake) rehabbing and confessing might not work in getting him most of the latter back. But eventually 
it just might. At this point, Tiger remains a celebrity insofar as he remains a great golfer, and that will require more selfdiscipline than ever. The greatness that comes with talent and skillful self-discipline can make the dignity that comes with ordinary good superfluous.

The criticism of celebrities as negative "role models" is a staple of social conservatives. A generation ago (I use this example because I'm old) Vice President Dan Quayle criticized writers of the hit show "Murphy Brown" for allowing the lead character to have a baby out of wedlock. The character Murphy Brown, a celebrity TV journalist on the show, was, in fact, a role model for many ambitious American women. As socially conservative criticism Quayle's comments were flawed by the fact that Murphy Brown made a pro-life choice; she, to some extent put her baby before her career, and certainly before her personal freedom. The real issue is that it's no big deal for a rich celebrity woman to have a baby on her own, but that's not the case for most women. A conservative would say that TV shouldn't promote the celebrity separation of parenting from marriage. A pro-choice critic might actually complain that it was too easy for Murphy to keep her productive and fulfilling way of life while not having an abortion. For ordinary aspiring career women, the choice is at least somewhat starker.

Either way, the problem is that if we look up to celebrities as role models, we might be persuaded to destroy our own lives by attempting to live as freely or irresponsibly as they do. And the "culture of celebrity" creates the impression that the only reason we must be more responsible is that we lack the freedom from necessity that celebrities enjoy. It also creates the impression that we're not allowed to rank celebrities according to their moral fiber or admirable exercise of personal responsibility toward others (above, of course, not grossing us out by letting themselves go). That may be why, in fact, that in general we allow celebrities to be trashier than ever, and why they bother less than ever to hide their trashiness from us. And their shamelessness-abetted by the shameless media that won't give them the space even to pretend to be moral exemplars - is one reason why very young people who are lost enough to be stuck with video searches for role models way too often look, talk, and act trashier than ever. (Saying more here would require beginning with Britney and Britney types and the little girls who seem to be devoting their lives to being them).

Every judgmental observation of that kind admits of many edifying exceptions and nuanced qualifications, such as the relatively innocuous (so far) Taylor Swift among the mainstream teen-oriented performing celebrities and the pop Christian counterculture that attracts a significant segment of the young (especially, but not only, in my southern part of our country). It's true that even Taylor doesn't claim to be all about chastity, and too much of pop Christianity is more about emotion than habituation.

I can honestly say that I can't think of a young person I know who is obviously "going somewhere" who is more than amused or diverted by celebrities. Certainly the newlyminted professors who in their postmodern way are developing "celebrity theory" don't actually orient their personal lives around the persons they study. As far as I can tell, the intelligently artistic young used to take musical celebrities - such as Dylan or the Beatles or the Grateful Dead-more seriously than they do now. That may bealthough there are throwback exceptions such as Bono and Springsteen (both well past their primes) — because musical celebrities don't take themselves as seriously as role models as they used to do.

And even (or especially) ordinary people know that when celebrities possess a singular artistic greatness, their lives are not for envy or imitation. Two of the most revered and beloved American celebrities were Elvis Presley and Michael Jackson. Certainly their deaths plunged us into grief in a way rivaled only by the assassination of a president. Americans were "connected" to Elvis and Michael at least as much as they were to President Kennedy. But everyone knows that their lives were sad, screwed up, and self-destructive, and their young deaths were virtually suicides. Nobody models his or her family after Elvis's or Michael's. And everyone knows they used their great wealth to gratify extravagantly their bizarre personal fantasies. In Michael's case, everyone thinks they know (whether it's really true or not) that much of his wealth was consumed by buying his way out of criminal self-indulgence with children, and both of them, it seems, couldn't help but be degradingly, desperately addicted to drugs. We know somehow that the greatness of Michael and Elvis was inseparable from their misery, and their deaths filled us with love based on understanding-or maybe on the misunderstanding that Michael and Elvis died for us.

Anyone would love to sing like Elvis or dance like Michael, and it's even fun to dress up like them. But hardly anyone would want to live or really be just like either of them. Still, Michael and Elvis, in their ways, were genuinely spiritual men. Elvis's big love, we know, was gospel music, which he kept rather personal or private. Michael was quite the humanitarian. And unlike, say, Lady Di, he put hundreds of millions of his own dollars where his mouth was. He certainly energized the "We are the World" impulse in millions, and that he managed to be both incorrigibly shy and completely unable to hide his heart from the world was genuinely moving.

Shifting, briefly, to a deeper version of celebrity greatness, we can all say we want to be troubled enough and spiritual enough to appreciate the music of Johnny 
Cash. But who would want to go through the hell of actually being Johnny Cash? (We can say the same, of course, about Charlie Parker and Thelonious Monk.) It's only when celebrity is detached from singular talent and some kind of greatness of soul that the "role model" problem emerges in a big way.

Celebrity greatness, being self-absorbed or irresponsible, is still easily distinguished from political greatness. Politicians (or, better, political leaders) either aren't or are more than celebrities. President Obama is quite the celebrity, but he's more than that. (Before he ran for president, it wasn't so clear he was more than that.) Bill Clinton, Al Gore, and Mike Huckabee are now merely celebrities. Sarah Palin, because the shameless media imposed the burdens of celebrity on her, was stuck with (and really enjoyed) skillfully making the transition from politician to celebrity. Being governor of Alaska was boring and paid poorly; becoming president was and will continue to be a most improbable long shot, but now she's rich and famous and commands the media's attention in all its dimensions. Palin, like Lady Di, is amazingly adept at linking her celebrity status to causes beyond herself, but increasingly the content of the cause seems secondary.

John Edwards was a slick celebrity lawyer who passed for a while as a politician; that's why we needed the National Enquirer to let us in on what he was up to all along. Political commentators, such as Rush Limbaugh, Glenn Beck, Jon Stewart, and Keith Olbermann are celebrities and nothing more; they're judged for their entertainment value. That's not to say they don't influence public opinion, but that they do so with blithe irresponsibility.

We doubt politicians really are more trustworthy than celebrities, but we demand that they be so. We expect them to behave more responsibly in their personal life (although the path-breaking Clinton narrowed the gap between celebrity and politician here), and we hold them accountable for what they actually do in power. The best way they have of being respected - or even being popular - is by being effective. It's amazing, in a media-driven, high-tech democracy, that more celebrities don't morph into politicians, and it's equally amazing that so many politicians perform badly or are so boring on television. Few politicians have what it takes to morph into celebrities. (The boys from Arkansas, Clinton and Huckabee, are much more quick, glib, and entertaining than just about all politicians, and it helps, of course, that Mike was trained as and excelled as a preacher and that Bill also remains fluent in "evangelical").

Schwarzenegger is a rather singular example of an outstanding celebrity actor who became a genuinely responsible political leader. Some postmodern studies suggest that people voted for Arnold because they couldn't tell the difference between the real man and the invincible action hero from the movies. But everyone now knows no mere man who plays action heroes could keep California from tanking. Then there's the very singular case of Reagan - the bad actor who became a great president. Fred Thompson reminded us that most bad actors who look like presidents shy away from the arduous work required actually to be a political leader. (Note, for the record, that, although the overwhelming number of celebrities are Democrats, examples of celebrity statesmanship are usually Republican).

Celebrities, of course, use the stage they've been given to express their political opinions (who wouldn't?!), and they are often irresponsibly quite self-righteous about the ignorance and corruption of those who run the government. As artists, they're especially contemptuous of Republicans, who are vulgarly obsessed with money and cater to "fundamentalist" and patriotic or anti-artistic, anti-liberationist opinion. But they're indulgent of Democrats who look down on folks in the heartland for desperately clinging to their guns and their God from the heights of celebrity affairs on the West Coast.

Celebrities characteristically engage in the silly "literary politics" that used to be reserved to poets and novelists and other more genuine bohemians. They usually aren't particularly well-educated and informed. They're even more easily seduced by conspiracy theories than ordinary people. We can turn, for example, to Charlie Sheen and Rosie O'Donnell to learn that 9/11 was really the secret plot of the American government. And celebrities love the sovereign disdain for the facts in pursuit of the conspiratorial "truth" that characterizes the engaging "narratives" of Michael Moore and Oliver Stone. Living in huge houses hanging off the sides of hills in the overpopulated and earthquake-prone California desert, they're especially concerned about the future of the planet, and they unreservedly admire the $\mathrm{Al}$ Gore who designed his account of an inconvenient (and very alarming) truth for their edification. Celebrities regularly display their pseudosophistication on Bill Maher's show, certain they're on the vanguard of moral and political enlightenment. None of this is to say that celebrities have much more impact on the outcome of elections than other very rich people. Celebrities, like philosophers in an unjust country, don't desire and aren't compelled to rule. It's only fair to add that many of the causes celebrities so generously fund to display their class have done much good for real people (as well as other species and nature as a whole).

All this celebrity stuff wouldn't have surprised the leading commentator on America and democracy's most genuine (or sympathetically but truthfully critical) friend, Alexis de Tocqueville. Tocqueville said democracy turns 
even art and literature into industries, and people turn to them less for profound truth and moral guidance than for relaxation or diversion from their stressful, productive, restless lives. That means, of course, that democratic people depend on the doings of celebrities for emotional relief, and that they usually don't have what it takes to esteem art and literature with the leisurely seriousness that the great works deserve. People who enjoy reading People and even Entertainment Weekly (including me) usually know that nothing crucial or authentically momentous is being displayed for them there. Those skillfully produced publications aim not to tax the mind or even enlarge the heart.

Many critics of democracy say that celebrities have replaced real greatness - true artists and true heroes. And Tocqueville observed that democracy causes us to doubt the reality of statesmen and heroes; profound and admirable personal greatness are too troubling and too dangerous as exceptions to our egalitarian rules. It's also true enough, as Tocqueville adds, that in an impersonal, egalitarian, bureaucratic, high tech, commercialized, commodified, centralized world, what outstanding individuals do is less important as a cause of change than "forces," such as technological development, the market, and public opinion. Due to the beneficial power of these forces, ordinary life is clearly more comfortable and secure and seemingly less heroic. We only need heroes, we often think, when modern life breaks down, and, even with the economic downturn and the continuing possibility of terrorism, we think we've figured out how to make it break down less and less often. For those whose heroes have always been cowboys, these are probably the worst of times in America. The Marines and Special Forces who heroically protect us every day think of themselves as more alienated from mainstream, self-indulgent, consumerist American culture than ever. Certainly the distance between them and the "culture of celebrity" continues to grow.

But we still know artistic greatness and artistic integrity when we see them. Even in the world of popular music, we admire the steadfast distance between Van Morrison, Joni Mitchell, and even Bob Dylan, and various fashionable (including fashionably political) currents. (We also notice that they show us that the true artist needn't be neurotic nor die young.) We also notice the fall of Paul Simon and even Springsteen into the fashionable and politically correct world of celebrity. (To be fair to Bruce, the longing remains to celebrate heroes, but once he left the real world of Jersey and Jungleland, he can't find them).

Not only that, but we still continue to recognize heroes for who they are and rank them above celebrities. That's why there persists a strong market for movies about the men who fought in World War II. And everything Clint Eastwood does shows us the moral ambiguity and deep nobility of heroic courage; no American, except celebrity critics and celebrity Academy Award voters, could be unmoved by Gran Torino. Americans remain both democratically open and nobly resistant to sophisticated deconstruction of our allegedly heroic Founding Fathers. We're repeatedly told that we ordinary people and especially ordinary celebrities these days are better than them; they were racist, sexist homophobes and we're not. But most Americans still know that their singular courage and foresight will always deserve our deep gratitude. For celebrity displays of patriotic gratitude, we, it's true, have to move from LA to Nashville, to, for example, the Zac Brown Band's appreciation of who has protected our right to eat chicken fried steak on a Friday night. But country music, everybody really knows, remains, despite its commercialization and standardization, the most impressive and probably most influential form of American mass market music.

Country fans and even country stars also know that higher than patriotism is religion, and they're more about thanking the Lord than even thanking our Founders. And for real spiritual guidance, most of our celebrities, we know well enough, are useless. Scientology has not caught on, and the New Agey, pseudo-Buddhist, astrological kind of stuff so popular among the West Coast stars interests more than engages us. There's no denying that Avatar was both loads of fun and an unrivaled techno-accomplishment. But to what extent did it achieve its celebrity creator's intention of turning lives around in the direction of oneness of nature? Surely more Americans became different or better men and women as a result of the very personal Christian charity lovingly displayed by the Sandra Bullock character in The Blind Side. We know it's a telling sign of the superficiality and narcissism of "celebrity culture" that so few celebrities are serious Christians or orthodox Jews or Mormons or adhere to any faith that imposes a strong communal moral discipline on its members. For a while, we thought of Mel Gibson as a rather dazzling exception, but even his faith turned out to be too mixed up with celebrity vices to sustain our admiration.

All in all, I'm more sanguine than most celebrity theorists about Americans knowing well enough the limits of celebrity, while acknowledging that being stuck with celebrities is more a downside than not of democracy.

Peter Augustine Lawler is Dana Professor of Government at Berry College. His latest book is Homeless and at Home in America: Evidence for the Dignity of the Human Soul in Our Time and Place (St. Augustines Press). 